\title{
Economic contributions of pharmaceutical interventions by pharmacists: a retrospective report in Japan
}

\author{
Daiki Yasunaga, Yuichi Tasaka, Satoshi Murakami, Akihiro Tanaka*, Mamoru Tanaka and Hiroaki Araki
}

\begin{abstract}
Background: Pharmacists in Japan currently play a key role in patient hospital care. Their responsibilities include filling prescriptions, checking a patient's medication history, and providing appropriate information to other health care workers. More importantly, pharmacists' interventions can also result in reductions in adverse drug reactions (ADRs) and, ultimately, in cost savings. This study aimed to determine the economic value of such interventions at a hospital in Japan.

Methods: At a single Japanese hospital, we analyzed 1452 pharmaceutical interventions by pharmacists, including recommending antibiotic dosage regimens, attending ward rounds with multidisciplinary health providers, providing drug information, and reporting ADRs. We classified the interventions into 13 categories. Using data from the PreAVOID Report by the Japanese Society of Hospital Pharmacists, along with previous studies, we estimated the cost savings of the interventions.

Results: Various savings could be realized through appropriate interventions by hospital pharmacists. Based on the amount paid by the Pharmaceuticals and Medical Devices Agency, we calculated the cost savings associated with preventing serious ADRs as 21,400 USD (\$) per case. The cost savings for recommendations related to transvenous antimicrobial therapy amounted to $\$ 1900$ per patient. Pharmacists' interventions were able to prevent 12 cases of serious ADRs.

Conclusions: Determining the economic value of pharmacists' interventions is an important means of appraising the current role of hospital pharmacists. Our evaluation demonstrates the positive economic effects of pharmacists' interventions in a hospital setting.
\end{abstract}

\section{Background}

Pharmacists today play a greater role in providing pharmacotherapeutics to patients [1]. However, to date, the economic contribution of various pharmaceutical interventions in a medical setting has not been thoroughly investigated in Japan. In this study, we calculated the economic impact of pharmaceutical interventions, including multidisciplinary teamwork, using an evidence-based approach.

It has been reported that in the United States of America, $6.7 \%$ of the adverse effects resulting from pharmaceuticals administered to hospitalized patients are considered serious, and $0.32 \%$ are fatal [2]. Similar

\footnotetext{
* Correspondence: akiki@m.ehime-u.ac.jp

Division of Pharmacy, Ehime University Hospital, Shitsukawa, Toon, Ehime 791-0295, Japan
}

\section{Biomed Central}

(c) 2016 The Author(s). Open Access This article is distributed under the terms of the Creative Commons Attribution 4.0 International License (http://creativecommons.org/licenses/by/4.0/), which permits unrestricted use, distribution, and reproduction in any medium, provided you give appropriate credit to the original author(s) and the source, provide a link to the Creative Commons license, and indicate if changes were made. The Creative Commons Public Domain Dedication waiver (http://creativecommons.org/publicdomain/zero/1.0/) applies to the data made available in this article, unless otherwise stated.

figures have also appeared in a recent review [3]. Another US study has shown that patients who experience adverse effects have longer hospital stays and higher mortality rates than those who do not [4]. In addition, some studies have demonstrated that medical costs from pharmaceutical adverse effects are increasing annually [5, 6]. In 2011 in Japan, 959 cases of adverse drug reactions (ADRs) were referred to the ADR relief services of the Pharmaceuticals and Medical Devices Agency (PMDA). Those ADRs cost the PMDA $\$ 20,583,890$ [7]. In Japan, the PMDA provides a medical allowance for harm to health that results from incorrect use of drugs (e.g., diseases and disabilities requiring hospitalization caused by adverse effects of drugs at hospitals and clinics). 
The most important role of a pharmacist is to ensure effective, safe drug therapy for the patient. In preventing drug-related adverse events, the hospital pharmacist acts as a risk manager for hospitalized patients. Furthermore, the pharmaceutical evidence-based interventions of pharmacists play a useful role in medical treatment [8,9]. A ward-based pharmaceutical service was introduced as a medical treatment bonus after fiscal 2012 in Japan; since then, the role of the pharmacist in hospital wards has expanded. Pharmacists have a number of responsibilities on the ward, including filling prescriptions, monitoring patients' drug histories, avoiding drug interactions, providing drug information to medical staff, and recommending drug regimens. Pharmacists now also perform a pharmaceutical service for outpatients receiving chemotherapy. It has been reported that $\$ 565,664$ per year could be saved by avoiding serious ADRs through continuous pharmaceutical interventions by pharmacists in US emergency care [10]. In addition, Niwa reported that a savings of $301,290,758$ JPY $(\$ 3,012,907)$ per year per patient could be achieved by establishing a program to ensure the appropriate use of antimicrobial drugs in Japanese hospitals [11]. To date, however, no study has examined the economic impact of individual pharmaceutical interventions by pharmacists in Japan; therefore, this was the goal of the present study.

\section{Methods}

The study was carried out in accordance with the guidelines for the care for human study adopted by the Ethics Committee of Ehime University Hospital (Ehime, Japan; approval number 1408004 of the review board). This investigation focuses on a single hospital and is a retrospective report of pharmacy interventions at Ehime University Hospital. Therefore, we did not obtain written informed consent for study participation. As of March 2014, the hospital had 626 beds and 41 pharmacists. We analyzed pharmacy interventions, including recommending antibiotic dosage regimens, attending ward rounds with multidisciplinary health providers, providing drug information, and reporting ADRs. We examined a total of 1452 pharmaceutical interventions performed at Ehime University Hospital from April 2013 to March 2014. We recorded and stored interventions in a webbased severity reaction database built by the Japanese Society of Hospital Pharmacists (JSHP) [12]. We categorized the 1452 reports into 13 types, following the classification used in Hamblin et al. [10]: (1) avoidance of serious ADRs; (2) transvenous antimicrobial therapy interventions; (3) switch from intravenous to oral administration; (4) interventions concerning cancer chemotherapy; (5) avoidance of drug interactions; (6) renal dosing recommendations; (7) intravenous drug compatibility; (8) confirmation of medication history (presurgical cessation of antiplatelet drugs); (9) drug therapy consultation or recommendations; (10) monitoring recommendations; (11) ward rounds, multidisciplinary teamwork; (12) drug information; and (13) ADRs reported to the PMDA.

In view of the cost of ADRs to the PMDA, we estimated that there could be an average saving of $\$ 21,400$ through the avoidance of serious ADRs in Japan: $\$ 20,583,890$ (1 $\mathrm{USD}=100 \mathrm{JPY}) / 959=\$ 21,464)$. In this study, we defined serious ADRs as serious adverse effects described in the printed information inserts in the drug packaging. We determined the cost savings with recommendations for transvenous antimicrobial therapy-the dosage regimen of anti-methicillin-resistant Staphylococcus aureus (MRSA) drugs - with reference to the study by Niwa [11]. That report stated that daily savings of $\$ 272.37$ per patient could be realized using the recommendations for transvenous antimicrobial therapy. At the hospital in the present study, anti-MRSA drugs are administered for an average of 7 days. Therefore, approximately $\$ 1900$ per patient could be saved by appropriate pharmaceutical interventions $(\$ 272.37 \times 7=\$ 1906.59)$. With regard to the switch from intravenous to oral administration, we calculated the cost difference per day multiplied by the number of days of oral administration.

Hamblin et al. reported that 2.6-5.21 \% of pharmaceutical interventions, e.g., avoidance of drug interactions and attention to renal dosing recommendations, lead to the avoidance of serious ADRs [10]. We defined the economic contributions of individual pharmaceutical interventions based on Hamblin et al. and described the rate at which routine interventions could prevent serious ADRs (2.6-5.21\%). Adverse effects can occur with any drug, but such effects are particularly common with anticancer agents, and these drugs also represent the highest risk from the standpoint of reaction severity. Therefore, according to the risk of expression of ADRs, we classified previously described pharmaceutical interventions (4) to (9) into three categories: interventions for cancer chemotherapy, high-risk drugs exclude anticancer agents, and others. We defined the economic contribution for each pharmaceutical intervention. For interventions related to cancer chemotherapy, the contribution was approximately $\$ 1120(\$ 21,400 \times 5.21 \%=\$ 1118.27)$. The contribution for high-risk drugs was about $\$ 840(\$ 21,400 \times 3.91 \%$ [the intermediate value between $2.6 \%$ and $5.21 \%$ ] $=\$ 839.24)$. The contribution for others amounted to about $\$ 560(\$ 21,400 \times 2.6 \%=\$ 558.06)$. In this study, we defined high-risk drugs according to JSHP business guidelines for these drugs [12]. Furthermore, based on the Hamblin et al. report [10], the medical economic contributions of pharmaceutical interventions (10) to (13) were defined as $\$ 0$ (Table 1). 
Table 1 Classification of pharmaceutical interventions and cost savings

\begin{tabular}{|c|c|}
\hline Intervention type & Cost savings \\
\hline \multirow[t]{2}{*}{ 1. Avoidance of serious ADRs } & $\begin{array}{l}\text { Benefits paid by PMDA to sufferers of ADRs in 2013: USD } \$ 20,583,890 \\
\text { Number of incidents: } 959\end{array}$ \\
\hline & $\begin{array}{l}\text { Average amount: } \$ 21,464 \\
\text { i.e., } \$ 21,400 / \text { case }\end{array}$ \\
\hline 2. Transvenous antimicrobial therapy interventions & $\$ 272.37 /$ patient $/$ day $\times 7$ days ${ }^{a}=\$ 1906.59 /$ patient, i.e., $\$ 1900 /$ patient \\
\hline 3. Switch from intravenous to oral administration & $\begin{array}{l}\text { Difference in cost between intravenous and oral administration per day } \times \text { days of } \\
\text { oral administration }\end{array}$ \\
\hline $\begin{array}{l}\text { 4. Interventions concerning cancer chemotherapy } \\
\text { 5. Avoidance of drug interactions } \\
\text { 6. Renal dosing recommendations } \\
\text { 7. Intravenous drug compatibility } \\
\text { 8. Confirmation of medication history (presurgical cessation of } \\
\text { antiplatelet drugs) } \\
\text { 9. Drug therapy consultation or recommendations }\end{array}$ & $\begin{array}{l}\text { Likelihood that a general intervention leads to preventing an ADR ranges from } \\
2.6 \text { to } 5.21 \% \\
\text { Most risky drug therapy: cancer chemotherapy } \\
\$ 21,464 \times 5.21 \%=\$ 1118.27 \text {, i.e., } \$ 1120 / \text { case } \\
\text { Intermediate risky drug therapy: high-risk drugs defined by JSHP } \\
\$ 21,464 \times 3.91 \%=\$ 839.24 \text {, i.e., } \$ 840 / \text { case } \\
\text { Normal drug therapy: others } \\
\$ 21,464 \times 2.60 \%=\$ 558.06 \text {, i.e., } \$ 560 / \text { case }\end{array}$ \\
\hline $\begin{array}{l}\text { 10. Monitoring recommendations } \\
\text { 11. Ward rounds, multidisciplinary teamwork } \\
\text { 12. Drug information } \\
\text { 13. ADRs reported to PMDA }\end{array}$ & These types are not directly reflected in the cost estimation, i.e., $\$ 0$ \\
\hline
\end{tabular}

${ }^{a}$ The average number of days that anti-MRSA drugs were used at the study hospital

Multiple interventions for a single patient were counted as one intervention

$A D R$ serious adverse drug reaction, PMDA Pharmaceuticals and Medical Devices Agency, JSHP Japanese Society of Hospital Pharmacists

\section{Results}

Table 2 shows the results of the classified pharmaceutical interventions. We grouped the 1452 interventions into the 13 categories described above. There were 640 instances of drug information, e.g., information given to doctors, pharmacists, nurses, or other health professionals. We estimated the medical economic contribution from these pharmaceutical interventions to be $\$ 876,017$.

There were 12 instances of avoidance of serious ADRs, for which the savings were $\$ 256,800$ (Table 3). Chemotherapy accounted for seven cases and avoidance of renal failure for two cases. There were 172 cases of transvenous antimicrobial therapy interventions, primarily involving Therapeutic Drug Monitoring: 121 of vancomycin (VCM); 37 of teicoplanin (TEIC); six of patients who switched to TEIC from VCM or vice versa; one of linezolid (LZD) one of arbekacin (ABK); and six of others. Total savings were $\$ 325,080$. Regarding the change from intravenous to oral administration, voriconazole (VRCZ) featured twice and LZD four times. The administration period of the oral antimicrobial was 55 days for VRCZ and 32 days for LZD.

Figure 1 shows the interventions for cancer chemotherapy. There were 48 interventions for supportive therapy recommendations, 16 for checking prepared drugs, 12 for dosing recommendations, and six other interventions, with total savings of $\$ 91,840$. The interventions mainly involved suggestions of appropriate antiemetic drugs and avoidance of serious ADRs.

Table 4 presents the cases of avoidance of drug interactions, which represented savings of $\$ 33,040$. Three interventions involved contraindications for coadministration, and 55 concerned a combination of issues. Most drug interactions were related to absorption inhibition.

There were 50 cases of renal dosing recommendations: for the main drugs famotidine, allopurinol, and levofloxacin, there were 12,8 , and six interventions, respectively, with combined savings of $\$ 29,960$. Pharmacists were able to contribute to preventing renal function aggravation and various adverse effects, such as hypoglycemia, by decreasing the dosage of oral antidiabetic medication and changing to an agent other than loxoprofen sodium for patients with reduced renal function.

There were three cases involving intravenous drug compatibility, for the drugs heparin and fat emulsion, iron oxide and normal saline, and VCM and micafungin; the savings were $\$ 1960$.

Regarding drug therapy consultation or recommendations, there were 50 cases of discontinuing unnecessary drugs, 36 for the prevention of ADRs (except cancer chemotherapy), and 12 for sleep control, with savings of $\$ 112,000$. A further eight interventions were recorded for pain control, 15 for bowel motion control, and 18 for the correction of prescription errors. There were seven cases of contraindication, three for avoiding inefficient drug therapy, and 34 for other interventions according to the patient's condition (Fig. 2). Active pharmaceutical interventions depended on the state of the patient; for example, pain control and bowel motion control were commonly implemented interventions.

In all, 463 interventions concerned additional drugs. In $122(26.3 \%)$ cases, the dosage was decreased; there were 82 cases $(17.7 \%)$ of drug discontinuation and 78 
Table 2 Estimation of annual economic impact

\begin{tabular}{|c|c|c|c|c|c|c|}
\hline \multicolumn{3}{|c|}{ Intervention type } & \multirow{2}{*}{$\begin{array}{l}\text { Number } \\
12\end{array}$} & \multirow{2}{*}{$\begin{array}{l}\text { Cost savings assigned } \\
\text { per case (USD) } \\
21,400\end{array}$} & \multirow{2}{*}{$\begin{array}{l}\begin{array}{l}\text { Total } \\
\text { (USD) }\end{array} \\
256,800\end{array}$} & \multirow{2}{*}{$\begin{array}{l}\text { Intervention class } \\
\text { Quality/safety } \\
\text { improved }\end{array}$} \\
\hline 1 & Avoidance of serious ADRs & & & & & \\
\hline 2 & Transvenous antimicrobial therapy interventions & & 172 & 1900 & 325,080 & $\begin{array}{l}\text { Pharmacotherapy } \\
\text { improved }\end{array}$ \\
\hline \multirow[t]{2}{*}{3} & \multirow[t]{2}{*}{ Switch from intravenous to oral administration } & Voriconazole & 55 & 165.1 & 9078 & \multirow[t]{2}{*}{ Cost saving } \\
\hline & & Linezolid & 32 & 96.9 & 3099 & \\
\hline 4 & Interventions concerning cancer chemotherapy & & 82 & 1120 & 91,840 & $\begin{array}{l}\text { Pharmacotherapy } \\
\text { improved }\end{array}$ \\
\hline \multirow[t]{2}{*}{5} & \multirow[t]{2}{*}{ Avoidance of drug interactions } & High risk & 2 & 840 & 1680 & \multirow{2}{*}{$\begin{array}{l}\text { Pharmacotherapy } \\
\text { improved }\end{array}$} \\
\hline & & Normal & 56 & 560 & 31,360 & \\
\hline \multirow[t]{2}{*}{6} & \multirow[t]{2}{*}{ Renal dosing recommendations } & High risk & 7 & 840 & 5880 & \multirow{2}{*}{$\begin{array}{l}\text { Pharmacotherapy } \\
\text { improved }\end{array}$} \\
\hline & & Normal & 43 & 560 & 24,080 & \\
\hline \multirow[t]{2}{*}{7} & \multirow[t]{2}{*}{ Intravenous drug compatibility } & High risk & 1 & 840 & 840 & \multirow{2}{*}{$\begin{array}{l}\text { Pharmacotherapy } \\
\text { improved }\end{array}$} \\
\hline & & Normal & 2 & 560 & 1120 & \\
\hline \multirow[t]{2}{*}{8} & \multirow{2}{*}{$\begin{array}{l}\text { Confirmation of medication history (presurgical cessation of } \\
\text { antiplatelet drugs) }\end{array}$} & High risk & 13 & 840 & 10,920 & \multirow{2}{*}{$\begin{array}{l}\text { Quality/safety } \\
\text { improved }\end{array}$} \\
\hline & & Normal & 4 & 560 & 2240 & \\
\hline \multirow[t]{2}{*}{9} & \multirow[t]{2}{*}{ Drug therapy consultation or recommendations } & High risk & 34 & 840 & 285,60 & \multirow{2}{*}{$\begin{array}{l}\text { Pharmacotherapy } \\
\text { improved }\end{array}$} \\
\hline & & Normal & 149 & 560 & 834,40 & \\
\hline 10 & Monitoring recommendations & & 19 & 0 & 0 & $\begin{array}{l}\text { Pharmacotherapy } \\
\text { improved }\end{array}$ \\
\hline \multirow[t]{3}{*}{11} & \multirow[t]{3}{*}{ Ward rounds, multidisciplinary teamwork } & $\mathrm{ICT}$ & 28 & 0 & 0 & \multirow{3}{*}{$\begin{array}{l}\text { Quality/safety } \\
\text { improved }\end{array}$} \\
\hline & & NST & 45 & 0 & 0 & \\
\hline & & $\mathrm{PCT}$ & 52 & 0 & 0 & \\
\hline 12 & Drug information & & 640 & 0 & 0 & Provider education \\
\hline \multirow[t]{2}{*}{13} & \multirow[t]{2}{*}{ ADRs reported to PMDA } & & 4 & 0 & 0 & \multirow[t]{2}{*}{$\begin{array}{l}\text { Quality/safety } \\
\text { improved }\end{array}$} \\
\hline & & Total & 1452 & - & 876,017 & \\
\hline
\end{tabular}

ADRs serious adverse drug reactions, ICT infection control team, NST nutrition support team, PCT pain control team, PMDA Pharmaceutical and Medical Devices Agency

Table 3 Avoidance of serious adverse drug reactions

\begin{tabular}{|c|c|c|}
\hline No. & Case & Pharmaceutical intervention \\
\hline 1 & Renal function worsening due to a combination of fibrates and statins & Discontinue fibrates \\
\hline 2 & $\begin{array}{l}\text { Lithium intoxication and acute renal failure in patients orally administered } \\
\text { lithium carbonate }\end{array}$ & $\begin{array}{l}\text { Measure blood lithium concentration and discontinue lithium } \\
\text { carbonate }\end{array}$ \\
\hline 3 & Liver dysfunction because of phenytoin & Change to other anti-epileptic drugs \\
\hline 4 & Hypoglycemia with oral diabetes drugs & Reduce dose of oral diabetes drugs \\
\hline 5 & Pancytopenia after an increase in carbamazepine dosage & Discontinue carbamazepine \\
\hline 6 & Bevacizumab administered to a patient with planned tooth extraction & Change to chemotherapy without bevacizumab \\
\hline 7 & Start of chemotherapy for grade 4 neutropenic patients & Postpone chemotherapy \\
\hline 8 & No blood test after chemotherapy (grade 4 neutropenia) & Recommend blood test \\
\hline 9 & Onset of grade 2 peripheral neuropathy after chemotherapy & Begin adjuvant analgesics \\
\hline 10 & Anaphylaxis by premedication at start of chemotherapy & Change premedication \\
\hline 11 & Start of chemotherapy for patients untreated for HBV-DNA-positive conversion & $\begin{array}{l}\text { Postpone chemotherapy and begin oral administration of } \\
\text { entecavir }\end{array}$ \\
\hline 12 & Start of chemotherapy for patients untreated for HBV-DNA detection & Begin oral administration of entecavir \\
\hline
\end{tabular}




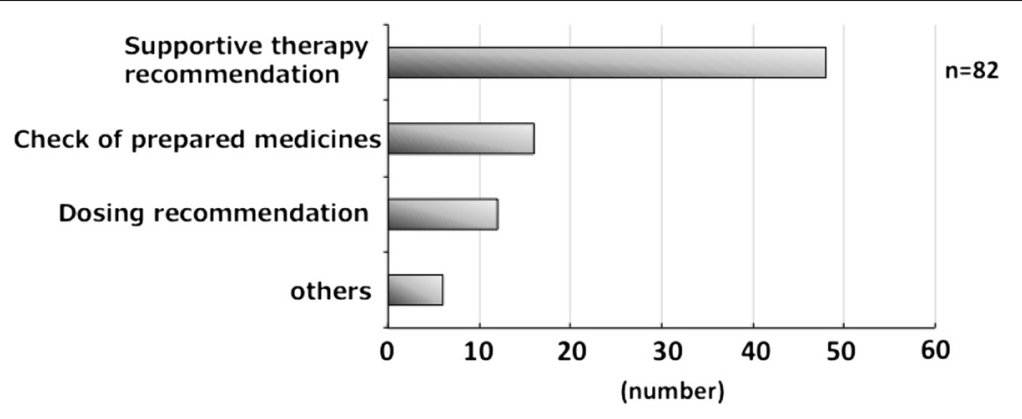

Fig. 1 Interventions for cancer chemotherapy

cases $(16.8 \%)$ of the drugs' being changed; 57 (12.3\%) cases represented a change in the dose regimen and 50 cases (10.8\%) other interventions (Fig. 3). All the interventions regarding monitoring recommendations included the recommendation for hepatitis B screening.

\section{Discussion}

One study has reported that pharmaceutical inquiries regarding prescriptions by community pharmacists were effective from a medical economic perspective, representing savings of $\$ 11,888$ [13]. In the present investigation, we conducted an economic evaluation of the effect of individual pharmaceutical interventions by clinical pharmacists. It is generally considered necessary to

Table 4 Avoidance of drug interactions

\begin{tabular}{lll}
\hline Contraindication for coadministration & Number \\
\hline Azathioprine & Febuxostat & 1 \\
Atorvastatin & Bezafibrate & 1 \\
Ferrous citrate & Albumin tannate & 1 \\
Combination of issues & Cefdinir & Number \\
Magnesium oxide & Oral new quinolone & 13 \\
Magnesium oxide & Cefdinir & 9 \\
Oral iron supplement & Levofloxacin & 6 \\
Oral iron supplement & Magnesium oxide & 5 \\
Oral iron supplement & Lactomin & 3 \\
Antimicrobial & Morphine & 1 \\
Pentazocine & Itraconazole & 1 \\
Famotidine & Clarithromycin & 1 \\
Tacrolimus & Magnesium oxide & 1 \\
Polystyrene sulfonate calcium & Sucralfate & 1 \\
Cefdinir & Levofloxacin & 1 \\
SM powder & & 58 \\
Total & &
\end{tabular}

SM Sankyo Magen Mittel

Oral iron supplement: ferrous citrate, ferrous fumarate, soluble ferric pyrophosphate

Antimicrobial: ampicillin/sulbactam, levofloxacin, erythromycin

Oral new quinolone: levofloxacin, minomycin, ciprofloxacin calculate costs induced by the adverse effects of drugs. However, it is very difficult to determine such costs, due to the great variety of drugs and their adverse effects. In this study, the individual outcomes in the absence of interventions were unknown. Therefore, we could not assess the expected economic contribution when an ADRs occurred because medical expenses vary greatly.

The damage relief system for ADRs offered by Japan's PMDA involves compensation contingent on appropriate use of the pharmaceuticals. We calculated the average compensation paid to a patient in Japan after a serious adverse effect at $\$ 21,400$, which is $\$ 6000$ higher than the figure reported by Hamblin et al. [10] One reason for the high cost of PMDA compensation is that it includes a patient benefit (The PMDA is an incorporated administrative agency under the Ministry of Health, Labour and Welfare, and we therefore considered it appropriate to include that benefit when calculating the economic contributions).

Our analysis of 1452 pharmaceutical interventions indicated that serious ADRs were avoided in 12 cases. This underlines the importance of the pharmacist in ward drug duties to ensure the safe management of patient medical treatment. In transvenous antimicrobial therapy interventions, most cases involved VCM, TEIC, and ABK. Approximately $70 \%$ of interventions concerned VCM cases. VCM is recommended as a first-line drug in MRSA infectious disease treatment guidelines in Japan. Switch therapy constitutes a change in administration of antimicrobial drugs from an intravenous drip to oral medication. It has been shown that switch therapy can reduce both medical expenses and length of hospital stay if introduced at an early stage of treatment [14]. From a cost perspective and because of their high bioavailability, we considered VRCZ and LZD to be suitable for switch therapy. With switch therapy, we estimated the cost savings at approximately $\$ 12,000$ due to cost differences in the drugs.

The most common intervention for cancer chemotherapy involved recommendations for supportive therapy. Therefore, we believe that pharmacists can prevent or 


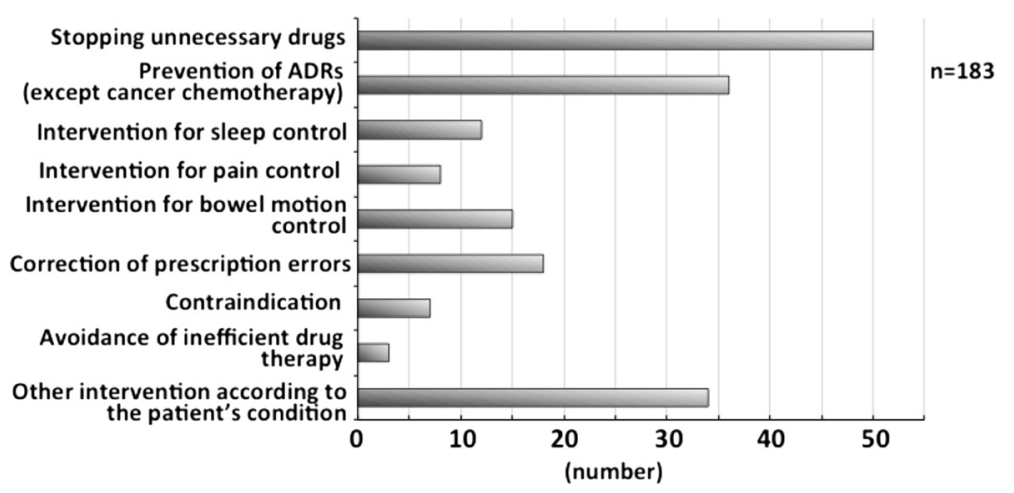

Fig. 2 Drug therapy consultations or recommendations

relieve the frequent onset of serious adverse effects of an anticancer agent by suggesting supportive therapy. Cancer chemotherapy often causes critical adverse effects. Accordingly, we assumed the rate of serious ADRs to be $5.21 \%$.

Contraindications for coadministration were extracted by the computer system and printed on prescriptions, so such risks were basically averted in our hospital. Because cases that involve only a prescription do not qualify as interventions in this study, only three cases of actual interventions occurred in this category.

Intravenous drug incompatibility not only reduces the titer of the drug, but also may cause a side effect. Because various infusions may be mixed in this route of administration, a careful chemical judgment is required. Only three cases occurred in this study, but ensuring compatibility is an important pharmaceutical intervention.

Regarding the confirmation of medication history, pharmacists commonly intervened in the discontinuation of preoperative anticoagulants and their postoperative readministration. For example, with angiotensin II receptor antagonists and angiotensin-converting enzyme inhibitors, it is recommended that the pharmacist cancel such prescriptions before an operation under practice guidelines for surgical medical care [15]. Similarly, many other drugs and anticoagulants should be discontinued before an operation. We would argue that such pharmacist interventions lead to the avoidance of adverse events during an operation and indicate a pharmacist's appropriate assessment of drug use in hospitals.

Pharmacists need to target their efforts particularly toward improving medication safety to prevent ADRs. Patients who experience an ADR require a longer hospital stay, which results in greater hospital costs [5, 16]. Any intervention that reduces ADRs will have a significant impact on patient care and health care costs. Drug costs can be directly increased or decreased by adding or removing a drug prescription. However, since the present study focuses on the economic contribution related to the prevention of adverse effect, we have not included the costs associated with adding or removing drugs.

There are four intervention types (Monitoring recommendations, Ward rounds, multidisciplinary teamwork, Drug information, ADRs reported to PMDA) for which we did not estimate economic effects in this study. Cooperation among medical care team members is known

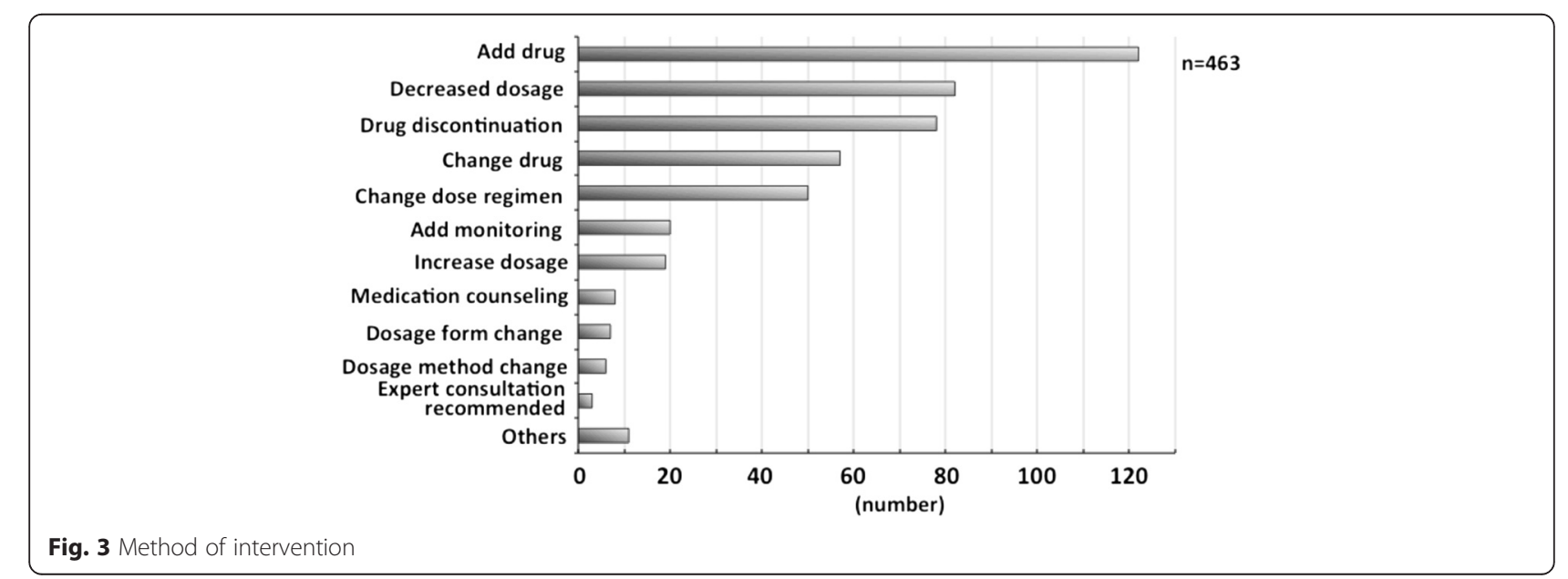


to be a strong contributor to symptom relaxation and improvement of the patient's QOL [17]. Regarding ward rounds and multidisciplinary teamwork, there were 28 cases of infection control team, 45 cases of nutrition support team, and 52 cases of pain control team. The intervention category of drug information, including education of ward staff, contained 640 cases. These interventions therefore offer many opportunities for economic contributions.

Lazarou et al. [2] found that $50 \%$ of the adverse effects of pharmaceutical products were preventable [2]. Bond and Raehl [4] estimated that $\$ 30$ billion a year could be saved by avoiding adverse effects-even if such effects were preventable in only approximately $50 \%$ of hospitals in the USA [4] (just a small number of hospitals are registered with the US adverse effect-reporting system). In Japan, the proportion of medical expenses attributed to ADRs is unknown. The present study is the first to investigate medical-related economic contributions in Japan, and we therefore believe that it contributes to the avoidance of adverse effects.

\section{Conclusions}

In this study, we conducted medical-related economic evaluations using an original estimation system. We calculated the effects of individual pharmaceutical interventions by pharmacists on reducing medical costs. In this way, we were able to determine the economic contributions of such interventions. Other pharmacists can use this work to evaluate interventions economically, using our classification and estimation system.

\footnotetext{
Abbreviations

ADRs, adverse drug reactions; LZD, linezolid; MRSA, anti-methicillin-resistant Staphylococcus aureus; PMDA, Pharmaceuticals and Medical Devices Agency; VCM, vancomycin; VRCZ, voriconazole
}

\section{Acknowledgements}

Language editing was performed by Edanz.

\begin{abstract}
Authors' contributions
DY contributed to data collection and analysis and wrote the manuscript. YT contributed to the study design and data analysis. SM contributed to data collection and analysis. AT conceived the study and revised the manuscript. MT contributed to the study design and management. HA contributed to the study design and revised the manuscript. All the authors read and approved the final manuscript.
\end{abstract}

\section{Competing interests}

The authors declare that they have no competing interests.

Received: 21 January 2016 Accepted: 14 June 2016

Published online: 19 July 2016

\section{References}

1. Tasaka Y, Tanaka A, Ido K, Tanaka M, Araki H. Estimation of the economic impact associated with pharmaceutical interventions. Jpn J Pharm Health Care Sci. 2014;40:208-14.

2. Lazarou J, Pomeranz BH, Corey PN. Incidence of adverse drug reactions in hospitalized patients: a meta-analysis of prospective studies. JAMA. 1998; 279:1200-5.
3. Miguel A, Azevedo LF, Araujo M, Pereira AC. Frequency of adverse drug reactions in hospitalized patients: a systematic review and meta-analysis. Pharmacoepidemiol Drug Saf. 2012;21:1139-54.

4. Bond CA, Raehl CL. Adverse drug reactions in United States hospitals. Pharmacotherapy. 2006;26:601-8.

5. Classen DC, Pestonik SL, Evans RS, Lloyd JF, Burke P. Adverse drug events in hospitalized patients. Excess length of stay, extra costs, and attributable mortality. JAMA. 1997;277:301-6.

6. Bates DW, Spell N, Cullen DJ, Burdick E, Laird N, Petersen LA, et al. The costs of adverse drug events in hospitalized patients: adverse drug events prevention study group. JAMA. 1977;277:307-11.

7. Pharmaceuticals and Medical Devices Agency(PMDA). http://www.pmda.go. jp. Accessed 27 Apr 2014.

8. Wakasugi H, Nakagiri M, Ishii J, Kaneko I, Takahasi K, Yano I, et al. Evaluation of providing drug information and clinical pharmacy intervention undertaken in hospital pharmaceutical care. Jpn J Pharm Health Care Sci. 2003;29(4):415-20.

9. Ide N, Gotou S, Mori M. Proposal for a new tool to evaluate clinical pharmacy practice based on the percentage of pharmaceutical interventions that influence medical treatments. Yakugaku Zasshi. 2008; 128(8):1215-20.

10. Hamblin S, Rumbaugh K, Miller R. Prevention of adverse drug events and cost savings associated with PharmD interventions in an academic level I trauma center: an evidence-based approach. J Trauma Acute Care Surg. 2012;73:1484-90.

11. Niwa T. Establishment of antimicrobial stewardship intervention to promote the appropriate use of antimicrobial injection in all inpatients and outcomes evaluation. Jpn J Pharm Health Care Sci. 2013;39:125-33.

12. Japanese Society of Hospital Pharmacists (JSHP). http://www.jshp.or.jp/ (2007-2015). Accessed 25 Nov 2013.

13. Shikamura Y, Oyama A, Takahashi J, Akagi Y, Negishi K, ljyuin K, et al. Medical economics research on awareness of community pharmacists about raising pharmaceutical questions regarding prescriptions issued by physicians. Yakugaku Zasshi. 2012;132(6):753-61.

14. Desai $M$, Franklin BD, Holmes AH, Trust $S$, Richards $M$, Jacklin A, et al. A new approach to treatment of resistant gram-positive infections: potential impact of targeted IV to oral switch on length of stay. BMC Infect Dis. 2006;6:94.

15. Guidelines for the management of hypertension 2014. Japanese Society of Hypertension. Tokyo: Life Science Publishing

16. Suh DC, Woodall BS, Shin SK, Santis ERHD. Clinical and economic impact of adverse drug reactions in hospitalized patients. Ann Pharmacother. 2000;34: 1373-9.

17. Masumi N, Kinomi Y, Mamiko S, Miwa T, Toshiaki N, Kazuyoshi H. Evaluation of palliative care team activities at the saitama cancer center. Jpn J Pharm Palliat Care Sci. 2009;2:25-8.

Submit your next manuscript to BioMed Central and we will help you at every step:

- We accept pre-submission inquiries

- Our selector tool helps you to find the most relevant journal

- We provide round the clock customer support

- Convenient online submission

- Thorough peer review

- Inclusion in PubMed and all major indexing services

- Maximum visibility for your research 